\title{
Quality Assessment of Compounded 17-hydroxyprogesterone Caproate
}

\author{
Justine Chang, MD1, Yang Zhao, $\mathrm{PhD}^{2}$, WenChen Zhao, MS², Raman Venkataramanan, \\ $\mathrm{PhD}^{2}$, and Steve N. Caritis, MD ${ }^{1}$ \\ ${ }^{1}$ Department of Obstetrics, Gynecology and Reproductive Sciences and Pharmaceutical \\ Sciences, University of Pittsburgh Schools of Medicine, Pittsburgh PA for the Obstetrical-Fetal \\ Pharmacology Research Units Network \\ ${ }^{2}$ Department of Pharmacy, Pittsburgh PA for the Obstetrical-Fetal Pharmacology Research Units \\ Network
}

\begin{abstract}
Objective-To evaluate the quality of compounded 17-hydroxyprogesterone caproate (17OHPC)

Study Design-Compounded 17-OHPC was obtained from 15 compounding pharmacies throughout the U.S. and analyzed for potency, impurities, sterility, and pyrogen status.

Results-Eighteen samples were supplied by 15 compounding pharmacies. The concentration of 17-OHPC in all samples was within the specification limits and all tested samples passed sterility and pyrogen testing. Only 1 of 18 samples was out of specification limits for impurities.
\end{abstract}

Conclusion-Compounded 17-OHPC obtained from 15 pharmacies throughout the U.S. did not raise safety concerns when assessed for potency, sterility, pyrogen status or impurities.

\section{Keywords}

compounded 17-OHPC; impurity analysis; potency; sterility and pyrogen status

\section{Introduction}

17-alpha-hydroxyprogesterone caproate (17-OHPC) reduces the risk of recurrent spontaneous preterm birth in women with singleton gestation and a prior preterm birth. ${ }^{1}$ Until recently this medication was only available from independent compounding pharmacies across the country. In February 2011, the FDA approved the New Drug Application of KV Pharmaceuticals to market 17-OHPC as Makena. ${ }^{2}$ The company initially set the price of Makena at $\$ 1500 /$ injection whereas the cost of compounded 17-OHPC prior to FDA approval was $\$ 10-\$ 15 /$ injection. The resultant public outcry led to congressional

\footnotetext{
(C) 2013 Mosby, Inc. All rights reserved.

Corresponding Author: Steve N. Caritis, MD, 300 Halket Street; Room 2229, Pittsburgh, PA 15213, Business Phone: 412-641-4874, Home Phone: 412-641-5256, Fax Number: 412-641-1133, scaritis@mail.magee.edu.

The authors report no conflict of interest

Condensation: Compounded 17-OHPC from 15 US pharmacies did not raise safety concerns.

Publisher's Disclaimer: This is a PDF file of an unedited manuscript that has been accepted for publication. As a service to our customers we are providing this early version of the manuscript. The manuscript will undergo copyediting, typesetting, and review of the resulting proof before it is published in its final citable form. Please note that during the production process errors may be discovered which could affect the content, and all legal disclaimers that apply to the journal pertain.
} 
hearings and universal condemnation of the company's pricing policies..$^{3,4,5}$ Consequently, the FDA issued a statement indicating it would not take enforcement action against compounding pharmacies that continued to produce 17-OHPC in order to allow continued patient access to this medication ${ }^{6}$.

A recent report by Chollet and Jozwiakowski from the Ther-Rx Corporation which markets Makena suggested that compounded 17-OHPC poses a risk as many unspecified impurities were identified in the active pharmaceutical ingredients (APIs) used to compound 17-OHPC and that the concentration of the compounded product was commonly not in the range of accepted potency ${ }^{7}$. The FDA conducted their own investigation and could not identify any major safety problems for compounded 17-OHPC. The FDA, however, stated that it was again applying its normal enforcement policy to compounded 17-OHPC. ${ }^{8}$

We undertook this study after the report of Chollet and Jozwiakowski and prior to the time the FDA undertook their investigation. ${ }^{7,8}$ Our purpose was to obtain compounded 17-OHPC formulations from compounding pharmacies throughout the United States and to analyze the product for potency (concentration), impurities, sterility and pyrogen status. Sterility and pyrogen status assessments of compounded 17-OHPC were not provided in the reports of the FDA or of Chollet and Jozwiakowski. ${ }^{7,8}$ Additionally, several differences in the assessment of compounded 17-OHPC were evident in those two reports.

\section{Materials and Methods}

This study has been deemed IRB exempt by the University of Pittsburgh IRB as it involves no patients or biological materials.

\section{a. Identification of compounding pharmacies for recruitment}

Twenty Maternal-Fetal Medicine specialists practicing in high-volume clinical centers (e.g., university hospital-based clinics or large group practices) were contacted to obtain information regarding the compounding pharmacies that were used to fill their patients' prescriptions of 17-OHPC. Many of these physicians were identified based on their participation as clinical investigators in various research networks.

\section{b. Recruitment of the compounding pharmacies}

Compounding pharmacists were contacted by study investigators or by the participating Maternal-Fetal Medicine clinicians and were asked to participate in the study. A representative sample of their compounded 17-OHPC was purchased and shipped to the University of Pittsburgh for testing. The funds for purchase of the compounded 17-OHPC came from the University of Pittsburgh at times that were not predictable. This uncertainty of time of purchase lessens the possibility that the pharmacies had any opportunity to provide anything other than a "representative sample" of 17-OHPC. Each pharmacist was then asked to participate in a brief survey regarding their compounding and quality assurance practices. The pharmacies' voluntary accreditation status with the Pharmacy Compounding Accreditation Board (PCAB) was assessed by reviewing the PCAB website of accredited pharmacies (www.pcab.org/accredited-pharmacies accessed on June 21, 2013). Samples $(n=3)$ were also utilized from a research pharmacy used by the Maternal-Fetal Medicine Units Network and the Obstetrical-Fetal Pharmacology Research Units Network in trials that used 17-OHPC. 


\section{c. Sample analysis}

Compounded 17-OHPC obtained from these various compounding pharmacies was stored at room temperature until analysis for content uniformity, impurity analysis as well as microbiological testing and pyrogen status.

\section{Content Analysis}

Content and impurity analysis were performed at the University of Pittsburgh using high performance liquid chromatography (HPLC) with a Waters 2695 Separations Module attached to a Waters 2998 Photodiode Array Detector 9. Aliquots of the samples were removed from the container in a laminar flow hood at room temperature and were tested to evaluate, in triplicate, concentrations of 17-OHPC, benzyl alcohol (a preservative) and benzyl benzoate (used to enhance solubility of 17- OHPC in castor oil). The sample was diluted with methanol or acetonitrile to a final 17-OHPC concentration of $50 \mu \mathrm{g} / \mathrm{mL}$. Twenty $\mu \mathrm{L}$ of this final solution was injected onto the HPLC. The concentrations of 17OHPC (at a wave length of $242 \mathrm{~nm}$ ), benzyl alcohol (at a wave length of $206 \mathrm{~nm}$ ), benzyl benzoate (at a wave length of $229 \mathrm{~nm}$ ), in each sample were quantified using corresponding standard curves. The calibration curves were generated by least-squares linear regression analysis of the peak areas versus concentration in the standard curve samples. The retention times of 17-OHPC, benzyl alcohol, and benzyl benzoate were 13.5, 7.0, and 7.9 minutes respectively, under the chromatographic conditions used.

\section{Impurity analysis}

Impurity analysis was also performed at the University of Pittsburgh. The same sample aliquots used for content analysis were analyzed for impurities. Quantification of the content of caproic acid was performed at $208 \mathrm{~nm}$. Quantification of 17-hydroxyprogesterone (17OHP) and the unspecified components in the sample were performed at $242 \mathrm{~nm}$ using the same chromatographic separation conditions used for 17-OHPC. The content of the other unspecified components was evaluated as the ratio of the area under the corresponding peak versus the area of 17-OHPC in the same sample. The percentage of each additional unspecified component in the test solution was calculated using the formula: percentage of component $=100 \times(\mathrm{Ac} / \mathrm{Ar})$, where $\mathrm{Ac}$ is peak area of the individual component and $\mathrm{Ar}$ is the peak area of 17-OHPC in the same test solution.

The HPLC method was validated for the determination of 17-OHPC and its related impurities of 17-OHP and caproic acid. ${ }^{9}$ The limit of quantification (LOQ) values for 17OHPC, 17-OHP and caproic acid were 62.5, 10 and 200 ng respectively on-column. Accuracy $(290 \%$ ) and precision (coefficients of variation $\leq 10 \%$ ) were evaluated by repeated analysis $(n=6)$ for 17-OHPC, 17-OHP and caproic acid. The analytical stability of 17-OHPC and 17-OHP in the HPLC auto-sampler was confirmed over a storage period of 72 hours at $8^{\circ} \mathrm{C}$, i.e. the sample compartment temperature. The test formulations of 17 OHPC showed no increase in the amount of impurities over a $72 \mathrm{~h}$ period in the autosampler.

\section{Pyrogen and sterility testing}

Sterility testing was performed by Eagle Analytical Services as described in U.S. Pharmacopeia Convention (USP) 71 using the membrane filtration procedure with Tryptic Soy Broth medium and Fluid Thioglycollate medium under $22.5 \pm 2.5^{\circ} \mathrm{C}$ and $32.5 \pm 2.5^{\circ} \mathrm{C}$, respectively at days 3,7 and 14 to test for bacteria, mold, yeast, and fungi in each sample. ${ }^{10}$

Endotoxin testing was performed by Eagle Analytical Services as described in USP 85 using the Turbidimetric procedure, with endotoxin inhibition/enhancement tests performed on each sample. Quantities of endotoxin are expressed in endotoxin units per milliliter (EU/ 
$\mathrm{mL}$ ). The Pyros Kinetix ${ }^{\mathrm{TM}}$ Incubating Kinetic Tube Reader (ACC, MA) was utilized; this test detects endotoxin levels to $0.001 \mathrm{EU} / \mathrm{mL} .^{11}$

\section{Results}

Twenty maternal-fetal medicine specialists were contacted within each geographic region of the country sampled. (Four physicians in the west, 3 in the northeast, 3 in the mid-Atlantic region, 6 in the south, 4 in the mid-west). Of the twenty physicians contacted, 15 agreed to participate. With the assistance of each of these physicians, a total of 17 compounding pharmacies were contacted and invited to participate in the study. Fifteen of these compounding pharmacies participated in the study by providing samples of 17-OHPC for testing (one pharmacy provided 2 samples and another pharmacy provided 3 samples). Twelve of these pharmacies additionally agreed to participate in a brief survey describing their compounding practices.

All of the formulations were clear, colorless or pale yellow and without any particulate matter at the time they were received. Each sample of 17-OHPC was tested for potency, impurities (both specified and unspecified), microbe and pyrogen status; the results are summarized in Tables 1-4. The label from each sample received reported a final concentration of $250 \mathrm{mg} / \mathrm{ml}$ of 17-OHPC. The average 17-OHPC concentration in these samples as determined by HPLC assay performed at the University of Pittsburgh was 251 $\mathrm{mg} / \mathrm{mL}$ (Table 1). All of the samples tested were within the acceptable specification limits for potency (90-110\%) and also as stated in the Makena New Drug Application (NDA). ${ }^{7}$ The average percentage of benzyl benzoate and benzyl alcohol were $47 \%$ and $2.1 \%$, respectively (Table 1). The mean concentration for benzyl benzoate is exactly as stated in the Makena NDA ${ }^{7}$ with very little scatter around the mean. The mean concentration of benzyl alcohol is identical to the Makena NDA but two of the samples were out of the specification limits for benzyl alcohol ${ }^{7}$.

Findings related to sterility and endotoxin testing are summarized in Table 2. Of the 18 formulations, 17 had adequate volume for sterility and pyrogen testing and all passed sterility testing, demonstrating no evidence of bacteria, mold, yeast or fungi. Of the 18 samples from 15 pharmacies, 2 did not have sufficient remaining volume after potency and microbial testing to allow for endotoxin testing. Of the remaining 16 formulations tested, nine had undetectable pyrogen level and seven had low levels of pyrogen, below that thought to be clinically relevant (i.e. these samples had pyrogen levels below the recognized threshold of $300 \mathrm{IU} / \mathrm{ml}$ ).

Specified additional components evaluated included caproic acid and 17hydroxyprogesterone; these components may be identified as impurities during testing. The quantity of each of these components is listed in Table 3. Caproic acid was detected in 4 samples with a final concentration of 30-50 ug/ml while in the other 14 samples, no caproic acid was detectable. All but 4 of the samples contained 17-hydroxyprogesterone with concentrations up to $179 \mathrm{ug} / \mathrm{ml}$. The amount of these "specified impurities" however is very low when compared to the amount of 17-OHPC; the highest percentage ratio for caproic acid was $0.003 \%$ and $0.03 \%$ for $17-\mathrm{OHP}$ (Table 3 ). The NDA specification limit is $<0.58 \%$ for caproic acid and for $<1 \%$ 17-OHP. Other measurable impurities which were "not identified' are listed in Table 4. The NDA specifications for 'unspecified impurities' call for levels $<0.2 \%$. In our cohort only 1 of 18 samples exceeded this level. The total amount of the 'unidentified impurities' was low and quantitatively amounted to an average of $0.16 \%$ of the amount of 17-OHPC (Table 4). No additional quantifiable peaks were evident in the chromatograms. 
Twelve of the 15 pharmacies agreed to participate in a brief survey describing their compounding practices. All of these pharmacies described scheduled or routine quality assessments of their compounded 17-OHPC which consistently including sterility testing as well as potency testing in $75 \%$ of respondents.

\section{Comment}

The present study evaluates compounded 17-OHPC formulations obtained from compounding pharmacies utilized by several academic Maternal-Fetal Medicine specialists throughout the United States. The 17-OHPC compounded for the MFMU trial reported by Meis et $\mathrm{al}^{1}$ and the product approved by the FDA (Makena) ${ }^{12}$ have identical ingredients which include $250 \mathrm{mg} / \mathrm{ml} 17-$ OHPC dissolved in castor oil with $46 \%$ benzyl benzoate to help dissolution and $2 \%$ benzyl alcohol as a preservative. Recently, Chollet and Jozwiakowski (whose research was supported by Thera-Rx which distributes the FDAapproved 17-OHPC product from KV pharmaceuticals) examined various compounded formulations of 17-OHPC. The FDA performed a similar analysis of compounded 17-OHPC using the samples of Chollet and Jozwiakowski and additional samples obtained independently from other compounding pharmacies. ${ }^{7,8}$ Our assessment of the compounded products we obtained differed in some key respects from the reports of the FDA and of Chollet and Jozwiakowski (Table 5). We sampled only the final product from various compounding pharmacies and did not obtain the individual components used in preparing the 17-OHPC directly from the suppliers. We did not test the Makena product but relied on the FDA-approved standards for the compounded product. Our interest was focused on the product patients received from the pharmacies used by the prescribing physicians. Our study also differed from the other two studies in that we performed microbiological and endotoxin testing whereas the other reports did not provide data on these parameters. Finally, we explored both specified (caproic acid and 17-OHP) and unspecified impurities and total impurities whereas the other two reports commented primarily on unspecified and total impurities. Although our sample size was small it was comparable to the size reported by the FDA and by Chollet and Jozwiakowsk. 7,8

We report that the compounded product from the selected pharmacies is consistent in potency with the product prepared for the MFMU study reported by Meis et $\mathrm{al}^{1}$ and the product approved by the FDA (Makena). We found very little variation among the compounding pharmacies in the drug concentration (potency) with a mean value of $251 \mathrm{mg} /$ $\mathrm{ml}$. All samples in our cohort were within the acceptable range (90-110\%) of declared potency on the label. In the FDA report, 1 of 13 (7.7\%) samples from 8 different pharmacies was sub-potent (potency was 80\%). On the other hand in the report of Chollet and Jozwiakowsk $17 \%$ of samples were out of the acceptable potency range. ${ }^{7}$ The FDA reanalyzed the samples initially analyzed by Chollet and Jozwiakowski and found that only $11 \%$ of samples ( 3 of 26) were out of the acceptable potency range and all of these were in the $115 \%$ range meaning concentrations were $115 \%$ higher than the $250 \mathrm{mg} / \mathrm{ml}$ target. ${ }^{7,8}$ Thus, dramatic differences were seen in the drug assay results performed on the same samples by the FDA and by Chollet and Jozwiakowski. ${ }^{7,8}$ Our results are more consistent with those of the FDA. ${ }^{7,8}$

In our cohort, unlike in the reports of Chollet and Jozwiakowski and the FDA, we performed microbiological and pyrogen testing and found that all compounded samples were free from microbial contamination and without significant levels of pyrogen. There exist many potential sources of pyrogen including water, equipment used in the product preparation and microbes. The assessment for pyrogens and microbes is highly relevant given the recent calamity attributed to the New England Compounding Center where contaminated products, apparently resulting from improperly preparation are alleged to have led to death and serious 
morbidity in many patients. ${ }^{13}$ Sterilization of compounded 17-OHPC is generally performed by membrane filtration or by dry heat. Sterilization is more difficult with an oil-based viscous compound compared to a water soluble compound. Although other methods of sterilization may prove effective, the current method most often used in preparing 17-OHPC for injection is filtration. This approach appears to be effective based on the findings we have reported here. As noted in the responses we received from some of the compounding pharmacies in our cohort, isolation or quarantining the compounded product for some period of time provides an additional safeguard against dispensing a contaminated product which may appear cloudy or may contain particulate matter which is visible in the solution.

In both the FDA report and the report of Chollet and Jozwiakowski, the compounded products obtained from compounding pharmacies in the United States were tested for impurities. ${ }^{7,8}$ These impurities are detected in the assay method as 'unspecified' peaks in the HPLC output. These peaks cannot be easily identified unless the nature of the compound is known, therefore these peaks are referred to as 'unspecified'. A summation of these peaks or individual peaks are generally compared to all peaks or to the primary product and expressed as a percentage. A level $<0.20 \%$ was defined by $\mathrm{KV}$ pharmaceuticals as an acceptable range for the FDA-approved 17-OHPC product (Makena). ${ }^{7}$ Chollet and Jozwiakowski reported that $17 / 30(57 \%)$ of $17-$ OHPC compounded by U.S. pharmacies in their cohort contained at least 1 impurity $>0.2 \%^{7}$. In the FDA report, only 7/26 (27\%) of the Chollet-retained samples contained unspecified impurities $>0.2 \%$ and $2 / 13(15 \%)$ of the samples obtained by the FDA from compounding pharmacies demonstrated unspecified impurities $>0.2 \%{ }^{8}$ The FDA report concluded that the level and character of the 'unspecified impurities' did not pose a risk. In our cohort only 1/18 samples had 'unspecified' impurities $>0.2 \%{ }^{8}$

Unlike in the reports of the FDA and Chollet and Jozwiakowski we reported results of our analysis of 2 components, caproic acid and 17-hydroxyprogesterone (17-OHP) which are not unexpected in a formulation of 17-OHPC and are not expected to cause harm or alter effectiveness of the active ingredient. These substances were present albeit in low concentrations relative to the concentration of 17-OHPC. In the report of Chollet and Jozwiakowski up to six unspecified impurities were seen in multiple formulations (typically one or two in each). Since they did not report specific impurity analysis, it is unclear if some of their 'unspecified' impurities were indeed caproic acid or 17-hydroxyprogesterone. In the FDA analysis 4 impurities were identified but they likewise did not assess the samples for specified impurities such as caproic acid and 17-hydroxyprogesterone.

In summary, we have analyzed formulations of 17-OHPC compounded by several pharmacies throughout the United States. We found that these compounded products provided labeled amount of the medication $(250 \mathrm{mg} / \mathrm{ml})$ which was free of microbial contamination and contained no or clinically insignificant levels of pyrogen. The amount of 'unspecified impurities' was well within acceptable limits, and caproic acid and 17-OHP were the most common components. Thus, the compounded products provided by these pharmacies fulfilled the USP and Makena NDA criteria required for formulations of 17OHPC. It is notable that the majority of these participating pharmacies endorse regular quality testing of their compounded17-OHPC formulations. In their report of June 2012, the FDA stated that it was applying its normal enforcement policies for compounded 17-OHPC and reiterated their general caution that the compounding of any medication should not exceed the scope of traditional pharmacy compounding. ${ }^{8}$ If a compounding pharmacy is utilized for preparation of 17-OHPC, a discussion with the pharmacy preparing the product is prudent with a focus on the policies and procedures used by the pharmacy to assure production of a high quality product. 


\section{Acknowledgments}

Dr. Chang and Dr. Y Zhao contributed equally to the work. We would like to thank the following individuals for their valuable assistance in identifying and/or recruiting pharmacies: Brenna Anderson, MD (Brown University); Leo Brancazio, MD (Duke University), Francesca Facco, MD (University of Pittsburgh); William Grobman, MD (Northwestern University); David Haas, MD (Indiana University); David Hackney, MD (Case Western Reserve University); Jay Iams, MD (the Ohio State University); Vanita D. Jain, MD (Delaware Center for Maternal Fetal Medicine, Christiana Care Hospital Services); Carol Lin, MD (Kaiser Permanente); Clifton Moore, MD (Ochsner Medical Center); Chris Robinson, MD (Medical University of South Carolina); Robert Silver, MD (University of Utah); David Stamilio, MD (Washington University); John Thorp, MD (University of North Carolina); Doug Woelkers, MD (University of California, San Diego)

Supported by a grant from the Eunice Kennedy Shriver National Institute of Child Health and Human Development (HD047905). The content is solely the responsibility of the authors and does not necessarily represent the official views of the Eunice Kennedy Shriver National Institute of Child Health and Human Development or the National Institutes of Health

\section{References}

1. Meis PJ, Klebanoff M, Thom E, et al. National Institute of Child Health and Human Development Maternal-Fetal Medicine Units Network. Prevention of recurrent preterm delivery by 17 alphahydroxyprogesterone caproate. N Engl J Med. 2003; 348:2379-2385. [PubMed: 12802023]

2. [Accessed 8/27/2013] http://www.fda.gov/NewsEvents/Newsroom/PressAnnouncements/ ucm279098.htm

3. [Accessed 8/27/2013] http://www.marchofdimes.com/news/statement-from-the-march-of-dimeson-17p.aspx

4. [Accessed 8/27/2013] http://www.preemieprimer.com/march-of-dimes-response-to-makena-pricingreveals-they-are-woefully-out-of-touch/

5. [Accessed 8/28/2013] http://www.brown.senate.gov/newsroom/press/release/following-makenaprice-hike-controversy-brown-asks-nih-director-how-can-we-stop-drug-manufacturers-fromexploiting-taxpayer-funded-research

6. [Accessed 8/27/2013] http://www.fda.gov/newsEvents/Newsroom/PressAnnouncements/ ucm 249025.htm

7. Chollet JL, Jozwiakowski MJ. Quality investigation of hydroxyprogesterone caproate active pharmaceutical ingredient and injection. Drug Development and Industrial Pharmacy. 2012; 38(5): 540-549. [PubMed: 22329865]

8. [Accessed 8/27/2013] http://www.fda.gov/NewsEvents/Newsroom/PressAnnouncements/ ucm308546.htm

9. Caritis SN, Zhao Y, Bettinger J, et al. Qualitative and quantitative measures of various compounded formulations of 17-alpha hydroxyprogesterone caproate. Am J Obstet Gynecol. 2013; 208:470.e1-5. 74-80. [PubMed: 23453884]

10. [Accessed 8/27/2013] http://www.eagleanalytical.com/sitecontent/589/rapid-scan-rdi-bacteriamold-and-fungal-test/category/462/about-testing.aspx

11. [Accessed 8/27/2013] http://www.eagleanalytical.com/sitecontent/588/endotoxins/category/462/ about-testing.aspx

12. [Accessed 8/27/2013] http://www.fda.gov/ohrms/dockets/ac/06/slides/2006-4227S1-01-01Adeza.pdf

13. [Accessed 8/27/2013] http://www.acog.org/About\%20ACOG/Announcements/ACOG-SMFM $\% 20$ Update $\% 20$ on $\% 20$ New\%20England\%20Compounding\%20Center.aspx 


\section{Table 1}

Chemical analysis of 17-OHPC, benzyl benzoate, and benzyl alcohol from different compounding pharmacies.

\begin{tabular}{|c|c|c|c|c|}
\hline $\begin{array}{l}\text { Sample } \\
\text { No. }\end{array}$ & $\begin{array}{c}\text { 17-OHPC } \\
(\mathrm{mg} / \mathrm{mL})\end{array}$ & $\begin{array}{c}\text { Percentage } \\
\text { of labeled } \\
\text { concentration }\end{array}$ & $\begin{array}{l}\text { Content of Benzyl } \\
\text { Benzoate, } \%\end{array}$ & $\begin{array}{l}\text { Content of Benzyl } \\
\text { Alcohol, \% }\end{array}$ \\
\hline 1 & 239 & 96 & 49 & 2.2 \\
\hline 2 & 253 & 101 & 46 & 2.0 \\
\hline 3 & 261 & 104 & 47 & 2.3 \\
\hline 4 & 260 & 104 & 48 & 1.9 \\
\hline 5 & 251 & 100 & 51 & 2.1 \\
\hline 6 & 244 & 98 & 46 & 2.8 \\
\hline 7 & 244 & 98 & 43 & 2.1 \\
\hline 8 & 255 & 102 & 44 & 2.6 \\
\hline 9 & 254 & 102 & 44 & 1.9 \\
\hline 10 & 247 & 99 & 46 & 1.9 \\
\hline 11 & 265 & 106 & 48 & 2.3 \\
\hline 12 & 265 & 106 & 49 & 2.1 \\
\hline 13 & 251 & 100 & 47 & 2.0 \\
\hline 14 & 247 & 99 & 48 & 1.7 \\
\hline 15 & 248 & 99 & 48 & 1.9 \\
\hline 16 & 243 & 97 & 49 & 2.0 \\
\hline 17 & 243 & 97 & 46 & 2.0 \\
\hline 18 & 243 & 97 & 45 & 2.1 \\
\hline Mean \pm SD & $\begin{array}{l}251 \pm 8 \\
\text { CV } 3 \%)\end{array}$ & $\begin{array}{l}100 \pm 3 \\
(\mathrm{CV} 3 \%)\end{array}$ & $\begin{array}{c}47 \pm 2 \\
(\mathrm{CV} 4 \%)\end{array}$ & $\begin{array}{l}2.1 \pm 0.3 \\
(\mathrm{CV} 1 \%)\end{array}$ \\
\hline $90 \% \mathrm{CI}$ & $248-254$ & $99-101$ & $46-48$ & $2.0-2.2$ \\
\hline Accepted Criteria * & $225-275 \mathrm{mg} / \mathrm{ml}$ & $90-110 \%$ & $46 \%$ & $1.7-2.3 \%$ \\
\hline
\end{tabular}


Table 2

Microbiological and endotoxin assessment of different formulations of 17-OHPC

\begin{tabular}{|c|c|c|}
\hline Sample No. & Sterility & $\begin{array}{l}\text { Bacterial endotoxin, } \\
\text { EU/mL }(<300 I U / m l)\end{array}$ \\
\hline 1 & Pass & $\mathrm{NA}^{*}$ \\
\hline 2 & Pass & 11.22 \\
\hline 3 & Pass & $<1$ \\
\hline 4 & Pass & 0.02 \\
\hline 5 & $\mathrm{NA}^{*}$ & $\mathrm{NA}^{*}$ \\
\hline 6 & Pass & 0.06 \\
\hline 7 & Pass & $<1$ \\
\hline 8 & Pass & $<1$ \\
\hline 9 & Pass & 0.006 \\
\hline 10 & Pass & $<1$ \\
\hline 11 & Pass & 0.005 \\
\hline 12 & Pass & $<1$ \\
\hline 13 & Pass & 0.078 \\
\hline 14 & Pass & $<1$ \\
\hline 15 & Pass & 0.013 \\
\hline 16 & Pass & $<1$ \\
\hline 17 & Pass & $<1$ \\
\hline 18 & Pass & $<1$ \\
\hline
\end{tabular}

* Testing not done because of limited sample volume $(<1 \mathrm{~mL})$.

Sterility testing carried out over 14 day time period 
Table 3

Specified impurity analysis of compounded 17-hydroxyprogesterone caproate (17-OHPC)

\begin{tabular}{ccccc}
\hline No. & $\begin{array}{c}\text { Conc. of CA } \\
(\mu \mathbf{g} / \mathbf{m L})\end{array}$ & $\begin{array}{c}\text { CA/17-OHPC } \\
\text { ratio }(\%)\end{array}$ & $\begin{array}{c}\text { Conc. of 17-OHP } \\
(\mu \mathbf{g} / \mathbf{m L})\end{array}$ & $\begin{array}{c}\text { 17-OHP/17-OHPC } \\
\text { ratio }(\%)\end{array}$ \\
\hline 1 & 30 & 0.012 & 242 & 0.10 \\
2 & 0 & 0 & 99.8 & 0.04 \\
3 & 0 & 0 & 99.0 & 0.04 \\
4 & 0 & 0 & 107 & 0.04 \\
5 & 30 & 0.012 & 179 & 0.07 \\
6 & 0 & 0 & 49.5 & 0.02 \\
7 & 0 & 0 & 52.0 & 0.02 \\
8 & 50 & 0.020 & 53.2 & 0.02 \\
9 & 0 & 0 & 0 & 0 \\
10 & 0 & 0 & 0 & 0 \\
11 & 30 & 0.012 & 47.3 & 0.02 \\
12 & 0 & 0 & 96.2 & 0.04 \\
13 & 0 & 0 & 152 & 0.06 \\
14 & 0 & 0 & 51.9 & 0.02 \\
15 & 0 & 0 & 52.4 & 0.02 \\
16 & 0 & 0 & 48.4 & 0.02 \\
17 & 0 & 0 & 0 & $0.03 \pm 0.03$ \\
18 & 0 & 0 & 0 & $0.02-0.04$ \\
\hline $90 \% \mathrm{CI}$ & $1.4-14.2$ & $0.001-0.005$ & $46.8-101$ & \\
\hline & & $0.003 \pm 0.006$ & $73.8 \pm 65.9$ & 0 \\
\hline
\end{tabular}

$\mathrm{CA}=$ caproic acid, $17-\mathrm{OHP}=17$ hydroxyprogesterone

Caproic acid (CA) measured at $208 \mathrm{~nm}$ and 17-OHP measured at $242 \mathrm{~nm}$ using standard curves generated with corresponding standards. 
Table 4

Unspecified impurity analysis of compounded 17-OHPC*

\begin{tabular}{|c|c|c|c|c|}
\hline Sample & Impurity $1 \%$ 17-OHPC & Impurity $2 \%$ 17-OHPC & Impurity $3 \%$ 17-OHPC & $\begin{array}{c}\text { Total unspecified impurities \% } 17 \text { - } \\
\text { OHPC }\end{array}$ \\
\hline 1 & 0.03 & 0.16 & 0.05 & 0.24 \\
\hline 2 & 0.11 & 0.14 & 0.04 & 0.29 \\
\hline 3 & 0.08 & 0.01 & 0.06 & 0.15 \\
\hline 4 & 0 & 0.04 & 0 & 0.04 \\
\hline 5 & 0.01 & 0.30 & 0.04 & 0.35 \\
\hline 6 & 0 & 0.20 & 0.02 & 0.22 \\
\hline 7 & 0 & 0.07 & 0 & 0.07 \\
\hline 8 & 0.04 & 0.03 & 0.01 & 0.08 \\
\hline 9 & 0 & 0.05 & 0.02 & 0.07 \\
\hline 10 & 0 & 0.06 & 0.02 & 0.08 \\
\hline 11 & 0.02 & 0.20 & 0.01 & 0.23 \\
\hline 12 & 0.04 & 0.03 & 0 & 0.07 \\
\hline 13 & 0.07 & 0.10 & 0 & 0.17 \\
\hline 14 & 0.07 & 0.08 & 0 & 0.15 \\
\hline 15 & 0.20 & 0.05 & 0.03 & 0.28 \\
\hline 16 & 0.02 & 0.16 & 0 & 0.18 \\
\hline 17 & 0 & 0.07 & 0 & 0.07 \\
\hline 18 & 0 & 0.07 & 0 & 0.07 \\
\hline Mean \pm SD & $0.04 \pm 0.05$ & $0.10 \pm 0.08$ & $0.02 \pm 0.02$ & $0.16 \pm 0.09$ \\
\hline Median & 0.02 & & 0.01 & 0.15 \\
\hline
\end{tabular}

Quantification at wavelength of $242 \mathbf{~ n m}$

Impurity 1 - retention time 2.9 minutes Impurity

Impurity 2 - retention time 3.8 minutes Impurity

Impurity 3 - retention time 6.7 minutes 
Table 5

Comparison of studies evaluating the quality of compounded 17-OHPC

\begin{tabular}{|c|c|c|}
\hline Chollet and Jozwiakowsk (October 2011) & FDA Report (June 2012) & Current Study \\
\hline \multicolumn{3}{|c|}{ ACTIVE PHARMACEUTICAL INGREDIENT (Hydroxyprogesterone caproate powder) } \\
\hline 10 samples evaluated & 16 samples evaluated & Not done \\
\hline 1/10 samples OOSL for content (HPLC) & 0/16 samples OOSL for potency & Not done \\
\hline $\begin{array}{l}8 / 9 \text { samples OOSL for unspecified } \\
\text { impurities }\end{array}$ & $\begin{array}{l}\text { 0/16 samples OOSL for total purity, } 16 / 16 \text { OOSL for } \\
\text { unidentified impurities, } 4 \text { impurities identified }\end{array}$ & Not done \\
\hline \multicolumn{3}{|c|}{ COMPOUNDED FORMULATIONS OF 17-OHPC } \\
\hline $\begin{array}{l}\text { 30 samples from } 30 \text { compounding } \\
\text { pharmacies }\end{array}$ & $\begin{array}{l}26 \text { "retained samples from C\&J tests and } 13 \text { FDA } \\
\text { samples from } 8 \text { compounding pharmacies }\end{array}$ & $\begin{array}{l}18 \text { samples from } 15 \\
\text { compounding pharmacies }\end{array}$ \\
\hline 5/30 samples OOSL for content (HPLC) & $3 / 26$ of C\&J samples OOSL for potency & 0/18 samples OOSL for content \\
\hline \multirow{3}{*}{$\begin{array}{l}\text { 17/30 samples OOSL for unspecified } \\
\text { impurities }\end{array}$} & 7/26 C\&J samples OOSL for impurities & 1/18 OOSL for impurities \\
\hline & 1/13 FDA-acquired samples OOSL for potency & \\
\hline & $\begin{array}{l}\text { 0/13 FDA-acquired samples OOSL for total impurities but } \\
\text { 2/13 samples OOSL for unidentified impurities stds for } \\
\text { impurities) }\end{array}$ & \\
\hline \multicolumn{3}{|c|}{ STERILITY \& ENDOTOXIN TESTING OF COMPOUNDED FORMULATIONS } \\
\hline Sterility testing not reported & Sterility testing not reported & $\begin{array}{l}\text { 18/18 samples passed sterility } \\
\text { testing }\end{array}$ \\
\hline Pyrogen testing not reported & Pyrogen testing not reported & $\begin{array}{l}16 / 16 \text { samples passed pyrogen } \\
\text { testing }\end{array}$ \\
\hline
\end{tabular}

OOSL= Out of specification limit

$\mathrm{C} \& \mathrm{~J}=$ Chollet and Jozwiakowsk 